\title{
Bioactive Surface Design Based on Functional Composite Electrospun Nanofibers for Biomolecule Immobilization and Biosensor Applications
}

ARTICLE in ACS APPLIED MATERIALS \& INTERFACES · MARCH 2014

Impact Factor: 5.9 · DOI: 10.1021/am5005927 · Source: PubMed

CITATIONS

5

5 AUTHORS, INCLUDING:

\section{Sema Demirci Uzun}

Middle East Technical University

7 PUBLICATIONS 29 CITATIONS

SEE PROFILE

\section{Suna Timur}

Ege University

146 PUBLICATIONS 1,338 CITATIONS

SEE PROFILE
DOWNLOADS

99
VIEWS

125
Tamer Uyar

Bilkent University

111 PUBLICATIONS 962 CITATIONS

SEE PROFILE 


\title{
Bioactive Surface Design Based on Functional Composite Electrospun Nanofibers for Biomolecule Immobilization and Biosensor Applications
}

\author{
Sema Demirci Uzun, ${ }^{\dagger}$ Fatma Kayaci, ${ }^{\ddagger}$, Tamer Uyar, $^{*, \dagger, \S}$ Suna Timur, ${ }^{\prime \prime}$ and Levent Toppare ${ }^{*, \dagger, \perp, \#, \nabla}$ \\ ${ }^{\dagger}$ Department of Polymer Science and Technology, Middle East Technical University, 06800, Ankara, Turkey \\ ${ }^{\ddagger}$ Institute of Materials Science and Nanotechnology, Bilkent University, 06800, Ankara, Turkey \\ ${ }^{\S}$ UNAM-National Nanotechnology Research Center, Bilkent University, 06800, Ankara, Turkey \\ ${ }$ Faculty of Science, Biochemistry Department, Ege University Bornova, 35100, İzmir, Turkey \\ ${ }^{\perp}$ Department of Chemistry, Middle East Technical University, 06800, Ankara, Turkey \\ \#Department of Biotechnology, Middle East Technical University, 06800, Ankara, Turkey

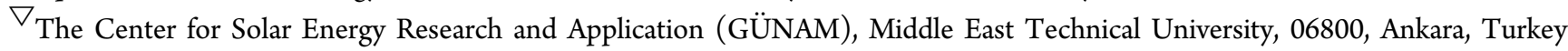

Supporting Information

ABSTRACT: The combination of nanomaterials and conducting polymers attracted remarkable attention for development of new immobilization matrices for enzymes. Hereby, an efficient surface design was investigated by modifying the graphite rod electrode surfaces with one-step electrospun nylon 6,6 nanofibers or $4 \%(\mathrm{w} / \mathrm{w})$ multiwalled carbon nanotubes (MWCNTs) incorporating nylon 6,6 nanofibers (nylon 6,6/4MWCNT). High-resolution transmission electron microscopy study confirmed the successful incorporation of

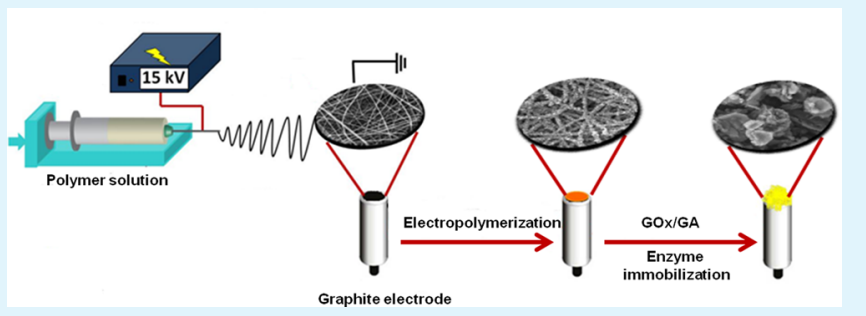
the MWCNTs into the nanofiber matrix for nylon 6,6/4MWCNT sample. Then, these nanofibrous surfaces were coated with a conducting polymer, (poly-4-(4,7-di(thiophen-2-yl)-1H-benzo[d]imidazol-2-yl)benzaldehyde) (PBIBA) to obtain a high electroactive surface area as new functional immobilization matrices. Due to the free aldehyde groups of the polymeric structures, a model enzyme, glucose oxidase was efficiently immobilized to the modified surfaces via covalent binding. Scanning electron microscope images confirmed that the nanofibrous structures were protected after the electrodeposition step of PBIBA and a high amount of protein attachment was successfully achieved by the help of high surface to volume ratio of electroactive nanofiber matrices. The biosensors were characterized in terms of their operational and storage stabilities and kinetic parameters $\left(K_{\mathrm{m}}{ }^{\text {app }}\right.$ and $\left.I_{\text {max }}\right)$. The resulting novel glucose biosensors revealed good stability and promising $I_{\max }$ values $(10.03$ and $16.67 \mu \mathrm{A}$ for nylon 6,6/PBIBA and nylon 6,6/4MWCNT/PBIBA modified biosensors, respectively) and long shelf life (32 and 44 days for nylon 6,6/PBIBA and nylon 6,6/4MWCNT/PBIBA modified biosensors, respectively). Finally, the biosensor was tested on beverages for glucose detection.

KEYWORDS: electrospinning, nylon 6,6 nanofibers, MWCNT, conducting polymer, covalent immobilization, glucose oxidase, amperometric biosensor

\section{INTRODUCTION}

Conducting polymers (CPs) are widely used macromolecular systems serving many application areas such as electrochromic devices, ${ }^{1}$ energy storage, ${ }^{2}$ and biotechnology ${ }^{3}$ in material science. Due to their noble electronic, chemical, and optical properties, these excellent conjugated structures lead to the development of new materials, rendering their properties convenient for technological research. ${ }^{4}$ Furthermore, superior properties of CPs can be generated for the desired purpose. Thus, molecular architecture plays a crucial role in the design and synthesis of these intelligent macromolecules. Considering their charming properties, CPs are also promising candidates for biomolecule immobilization in biosensing systems. ${ }^{5-7}$ The easy coating of CPs on different electrode surfaces and integration of various biomolecules into the CPs with different techniques enable us to construct new generation biosensors. $^{8-10}$ Additionally, the straightforward applicability, stability, and functionality of CPs permit the revolution of biosensors as faster and more economical devices in diagnosis and treatment.

In many biosensor systems, CPs are used as transducers allowing the biomolecule to get closer to the electrode surface due to their protein adsorption abilities. This intimacy between redox sites of the biomolecule and an electroactive CP-coated surface provides an increase in the overall current depending on

Received: January 27, 2014

Accepted: March 24, 2014

Published: March 24, 2014 
the efficient electron transfer. ${ }^{11}$ In addition to expansion of electronic properties of CPs, controlling the polymer morphology is a remarkable parameter for the biomolecule immobilization to promote the three-dimensional architecture of the biomolecule. ${ }^{12}$

For high reproducibility and sensitivity with short response time in clinical, food, environmental, and health care monitoring, biosensor architecture have been charming innovators for five decades. A convenient immobilization matrix selection and attachment of the desired enzyme to the surface by an appropriate technique have decisive roles in biosensing performance. Also, the selected electrode surface can be chemically modified to upgrade its physical and chemical properties upon demand. Hence, the interaction between enzyme and matrix can be successfully achieved to construct more stable and sensitive biosensors. The increase in functional group binding the biomolecule on the surface influences the enzyme loading. Since the transferred electrons resulting from the biochemical reactions between enzymes and substrate molecules increase due to high enzyme loading, the overall current response to the substrate is increased as expected. ${ }^{13}$

Carbon nanotubes (CNTs) have attracted great attention from many researchers after their discovery. ${ }^{14}$ Through the amazing mechanical and electronic properties, these nanosized cylindrical structures promote many application areas of materials science such as nanoelectronic devices, ${ }^{15}$ capacitors, ${ }^{16}$ superconducters, ${ }^{17}$ and nanocomposites. ${ }^{18}$ In particular, fast electron transfer ability, high aspect ratio, electrochemical stability, and biocompatibility properties of CNTs confirm the development of numerous materials in biosensing. ${ }^{19}$ In much research depending on manufacturing CNT electrodes for biosensing, these hollow cylindrical nanomaterials act as electrochemical transducers with their large electroactive sites. $^{20}$ Moreover, CNTs can behave as mediators, carrying out the electron transfer reactions when they are constructed as working electrodes. ${ }^{21}$ CNTs are mainly classified as singlewalled carbon nanotubes (SWCNTs), double-walled carbon nanotubes (DWCNTs), and multiwalled carbon nanotubes (MWCNTs). SWCNTs and DWCNTs include one or two graphene sheets, whereas MWCNTs have more confused structure with several cylindrical graphene layers. Since the high surface to volume ratio of MWCNTs promotes a large amount of enzyme immobilization, much more electron transfer reactions of proteins can be achieved on the surface. ${ }^{22}$

In recent studies on nanotechnology, it has been reported that the electrode performance is noticeably affected by their morphologies at nanoscale. ${ }^{23}$ Thus, biosensor performance can be developed by adjusting the surface morphology of the electrode. Among one-dimensional nanostructures, nanofibers produced by the electrospinning process dominate surface morphology with their high porosity and high aspect ratio. ${ }^{24}$ Hence, the electrospun nanofibers are promising nanomaterials as enzyme immobilization matrices, ${ }^{25}$ antibacterial surfaces, ${ }^{26}$ tissue templates, ${ }^{27}$ and drug deliverers ${ }^{28}$ in biotechnological advances. The nanofiber utilization as biomolecule immobilization matrices provides high surface area for loading depending on the high porous structure of the electrode surface. It is possible to generate reproducible and long time stable biosensors with nanofibrous platforms. ${ }^{29}$

Nylon has been an extensively used polymer for biosensing applications due to its good mechanical properties, chemical resistance, and stability and biocompatibility. ${ }^{30-32}$ However, nylon films need chemical or physical pretreatment for biosensing application because of its insulating property. ${ }^{30,31}$ Conversely, even without any preliminary treatment, electrospun nylon nanofibers have been found as promising materials for the sensing application due to their highly porous structure and large surface area. ${ }^{31,33,34}$ Therefore, they provide high loading, efficient immobilization, high sensitivity, stability, long lifetime, and excellent reproducibility. ${ }^{31,33,34}$ On the other hand, it is our experience that we are able to produce much thinner nanofibers (average fiber diameter below $100 \mathrm{~nm}$ ) from nylon 6,6 compared to other types of commercial polymers. Except for these, the excellent compatibility between MWCNTs and nylon that can greatly enhance the dispersion and the interfacial adhesion is another reason to select nylon nanofibers as the host matrix for the MWCNTs. ${ }^{35,36}$ Moreover, fine dispersion stability of the MWCNTs as well as good solubility of nylon were supplied using formic acid as the solvent. ${ }^{32}$ The functionalization of nylon nanofibers with MWCNTs may enhance the electron transfer ability, processability, dimensional stability, and mechanical strength of nylon. ${ }^{37,38}$ The unique mechanical and electronic properties of nylon/MWCNT composites have promising potential for the development of new generation materials in many application areas such as chemiresistors, ${ }^{39}$ dental composites, ${ }^{40}$ and microcatheters. ${ }^{41}$ However, to our best knowledge, there is no application for nylon 6,6/MWCNT nanofibers as an immobilization matrix in glucose detection.

Glucose monitoring is one of the most elaborated subjects in biosensing by researchers and the industry. Regularly detection of the glucose concentration in the blood plays a crucial role in the diagnosis and treatment of diabetes. Moreover, the determination of glucose concentrations in beverages is important for the food industry. Thus, development of low cost, high sensitive, stable, and rapid biosensors attracts more attention from many scientists. Glucose monitoring generally depends on amperometric measurements with the help of glucose oxidase $(\mathrm{GOx})$ in the presence of the molecular oxygen. Upon applied potential, $\beta$-D-glucose is oxidized to glucono- $\delta$-lactone which is subsequently hydrolyzed into gluconic acid. Afterwards, molecular oxygen is reduced to hydrogen peroxides. ${ }^{42}$

The motivation of this study is highly sensitive and stable novel bioactive surface development for biosensing. For this purpose, nylon 6,6 nanofibers incorporating MWCNTs (nylon 6,6/MWCNT) were prepared via an electrospinning technique. It was aimed to use the corresponding nanofibrous composite as a template for electropolymerization of 4-(4,7-di(thiophen-2yl)-1H-benzo[d]imidazol-2-yl)benzaldehyde (BIBA). We reported the synthesis and biosensor application of poly(BIPA) (PBIBA) in a previous work. ${ }^{43}$ Since PBIBA showed high affinity to glucose with good selectivity, the same polymer was preferred for construction of new biosensors. Besides its remarkable immobilization platform properties, this CP promotes the robust covalent attachment of the biomolecule to the surface. Therefore, PBIBA was electrochemically synthesized after the surface of the graphite electrode was modified with a nylon 6,6/MWCNT nanofibrous composite coating. To investigate the immobilization matrix characteristics of the surface, GOx was attached to the modified electrode as a model enzyme. Comparing the synergistic effect of two different composite-surface-formed materials on biosensing performance, nylon 6,6 nanofiber modified PBIBA-coated glucose biosensors were also fabricated. All biosensors were optimized to enhance the efficient electron transfer, and surface 
stability and amperometric current response were calibrated to different substrate concentrations for optimum biosensors. The accuracy and performance of the biosensors were tested for determining glucose concentrations in beverages.

\section{EXPERIMENTAL SECTION}

Since pristine MWCNTs include some metallic residues produced during the fabrication, they should be purified before their usage in biosensor applications. For oxidative purification, pristine MWCNTs were dispersed in $\mathrm{H}_{2} \mathrm{SO}_{4}: \mathrm{HNO}_{3}$ (3:1) solution, and the mixture were heated at $50{ }^{\circ} \mathrm{C}$ for $5 \mathrm{~h}$. Afterwards, this suspension was cooled at room temperature and filtered under vacuum conditions. For neutralization, MWCNTs were washed with distilled water via $\mathrm{pH}$ monitoring. Purified MWCNTs were dried at $80{ }^{\circ} \mathrm{C}$ overnight. ${ }^{44}$ Nylon 6,6 and nylon 6,6/MWCNT nanofibers were produced by electrospinning techniques to advance biosensor performance. Formic acid was used as the solvent to prepare electrospun solutions. Therefore, 8.0 wt \% nylon 6,6 was dissolved in the formic acid at room temperature, and clear solution was obtained by stirring for $3 \mathrm{~h}$. In the case of nylon 6,6/MWCNT solutions, 8.0\% (w/v) nylon 6,6 was dissolved in formic acid, and then different concentrations of MWCNT $(1.0 \%, 2.0 \%$, and $4.0 \%$, w/w, with respect to nylon 6,6 ) were added to nylon 6,6 solutions individually. The resulting nylon 6,6/MWCNT solutions were stirred for $5 \mathrm{~h}$ and sonicated for $1 \mathrm{~h}$ at the ambient conditions to obtain homogeneous solutions.

Each resulting solution was loaded to a syringe fitted with a metallic needle having $\sim 0.8 \mathrm{~mm}$ of inner diameter. During electrospinning, 1.0 $\mathrm{mL} / \mathrm{h}$ of feed rate was supplied to the solutions by the syringe pump. The high voltage power supply was used to apply a voltage of $+15 \mathrm{kV}$ for the electrospinning. Randomly oriented nanofibers were deposited on the circle base of cylindrical graphites that are fixed on a grounded stationary metal collector. The fiber collection distance between the graphite and the end of the tip was set to $10 \mathrm{~cm}$. The electrospinning process was carried out at $\sim 24{ }^{\circ} \mathrm{C}$ and $20 \%$ relative humidity in an enclosed Plexiglas chamber. Nylon 6,6/MWCNT nanofibers obtained from the 6,6 solution containing $1 \%, 2 \%$, and $4 \%(\mathrm{w} / \mathrm{w})$ MWCNTs are named as nylon 6,6/1MWCNT, nylon 6,6/2MWCNT, and nylon $6,6 / 4 \mathrm{MWCNT}$, respectively. The corresponding monomer synthesis was carried out as reported in a previous work. ${ }^{43}$ After the surface of all the electrodes was modified with the electrospun nanofibers, the PBIBA polymer was electrochemically synthesized on these nanofibrous coatings in the presence of $0.1 \mathrm{M} \mathrm{LiClO}_{4} / \mathrm{NaClO}_{4}(1: 1)$ in acetonitrile/dichloromethane $(5: 95, \mathrm{v}: \mathrm{v})$ in the potential range of $0.5-$ $1.6 \mathrm{~V}$ at a scan rate of $0.1 \mathrm{~V} \mathrm{~s}^{-1}$. The polymer-coated surfaces were washed with distilled water and phosphate buffer $(50 \mathrm{mM}, \mathrm{pH}=7.0)$ to remove organic residues. GOx ( $1.25 \mathrm{mg}$ in $5.0 \mu \mathrm{L}$ of $50 \mathrm{mM}$ sodium phosphate buffer, $\mathrm{pH}$ 7.0) was covalently immobilized on modified surfaces with the help of glutaraldehyde (GA) $(5.0 \mu \mathrm{L}, 0.1 \%$ in $50 \mathrm{mM}$ sodium phosphate buffer, $\mathrm{pH}$ 7.0). The enzyme biosensors were allowed to stand at room temperature for $2 \mathrm{~h}$. After all the electrode surfaces were dried, the unbound enzyme molecules and GA residues were removed from the surface by washing with distilled water.

All amperometric studies were carried out in sodium acetate buffer via application of $-0.7 \mathrm{~V}$ versus $\mathrm{Ag} / \mathrm{AgCl}$ electrode while mildly stirring at room temperature. In all experiments, current change due to the consumption of the molecular oxygen was detected; therefore, the difference between the baseline current and the steady state current before and after the addition of substrate was monitored. Throughout all the measurements a different volume of glucose solution was added to the buffer solution $(10 \mathrm{~mL}$ of $50 \mathrm{mM}$ sodium acetate, $\mathrm{pH} 5.5)$ at a steady state. After each measurement, the solution in the reaction cell was refreshed, and electrodes were washed with distilled water for removal of the residues. The biosensor performance was determined by adding various concentrations of glucose and calibrating them to different current responses recorded for each substrate concentration. On the other hand, the same volume of glucose solution was used during optimization studies. In all measurements, the average of three repetitive results was recorded for each glucose concentration, and standard deviations of these measurements were calculated.

\section{RESULTS AND DISCUSSION}

\subsection{Electrochemical Behaviors of Modified Surfaces.} To investigate the electrochemical behavior of each layer, a repeated potential scan technique was performed for modified surfaces in sodium acetate buffer $(50 \mathrm{mM}, \mathrm{pH} 5.5)$ at room temperature. High current responses in CVs for the modified surfaces can be correlated to their improved electron transfer ability. ${ }^{45}$ This situation provides the highly electroactive surfaces as the enzyme immobilization matrix in biosensing. The capacity for each modified surface was calculated from the cyclic voltammograms (CVs) of each polymer. It is well known that the total area of each cycle in the CV can be calculated by using a computer program and gives the total charge loaded to the surface which then converts this number to charge density. Considering the results of CVs illustrated in Figure 1, it is

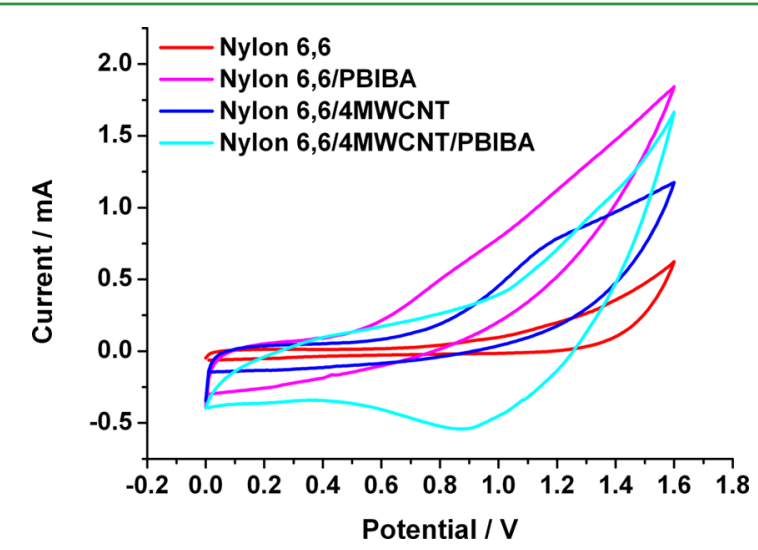

Figure 1. Cyclic voltammograms of layer-by-layer modified graphite electrodes (in sodium acetate buffer, $50 \mathrm{mM}, \mathrm{pH} 5.5,25{ }^{\circ} \mathrm{C}, 100 \mathrm{mV}$ $\left.\mathrm{s}^{-1}\right)$.

clearly seen that the loaded charges on the nylon 6,6 nanofibercoated surface increases remarkably after the electropolymerization of the BIBA monomer. The charges involved in the film formation were calculated as $3.46 \mathrm{mC}$ ( $77 \mathrm{~nm}$ thickness) for the nylon 6,6 nanofiber-coated surface and $12.70 \mathrm{mC}(282 \mathrm{~nm}$ thickness) for the PBIBA-coated nylon 6,6 nanofibrous surface. To upgrade the mechanical and electrochemical properties of the immobilization matrix, MWCNTs incorporating nylon 6,6 nanofibers were collected on a graphite electrode, and electrochemical properties were also examined via $\mathrm{CV}$ technique. The charges loaded on these surfaces were calculated as $9.52 \mathrm{mC}$ (221 nm thickness) for the nylon 6,6/ 4MWCNT nanofiber-coated surface and $18.35 \mathrm{mC}(408 \mathrm{~nm}$ thickness) for the nylon 6,6/4MWCNT/PBIBA nanocomposite modified layer. Furthermore, the oxidation and reduction potentials for all modified polymer structures can be calculated from CVs. According to the results in Figure 1, there is no remarkable difference between the oxidation potential of each surface. For nylon 6,6 polymer oxidation potentials were determined as +1.17 and $+1.20 \mathrm{~V}$ before and after electrodeposition of PBIBA, respectively. Due to the high conductivity of MWCNTs, incorporating them into the nylon 6,6 polymer has a significant effect on current and charge in comparison with nylon 6,6 and its nanocomposite with PBIBA. ${ }^{46}$ On the other hand, the oxidation potentials of nylon 6,6/4MWCNT and nylon 6,6/4MWCNT/PBIBA nanostructures (which were calculated as +1.19 and $+1.23 \mathrm{~V}$, respectively) showed a slight increase compared to nylon 6,6 and nylon 6,6/PBIBA based 
samples. Nanofibers allow obtaining a large surface area on even small volume depending on their high porosity stacking. This organization on the corresponding electrode has a vital importance to be easily arranged for an efficient morphology of the protein immobilization platform. As expected, the amount of electroactive species on the surface was drastically increased after PBIBA was coated in nanofiber-modified layers. Due to the synergy of nanomaterials, proposed $\mathrm{CP}$ was oriented to generate excellent electron transfer on the surface. Moreover, the well-organized nanofibrous composite coatings that were created with their powerful electronic characteristics and high stability needed an efficient enzyme immobilization.

3.2. Optimization Studies. The thickness of the immobilization matrix should be optimized to enhance the biosensor performance. It is an important parameter that is adjusted with the scan number during electropolymerization. The nanofiber-modified electrodes were prepared with different scan numbers of CP (varied 10 to 60 cycles) to determine the relation between polymer thickness and biosensor performance. The corresponding glucose biosensors based on nanofibrous composite surfaces were constructed and tested for the equal amount of substrate $(0.4 \mathrm{mM}$ glucose $)$ in amperometric measurements (Figure 2). During the biosensor fabrication step, all parameters except scan rate were kept constant.

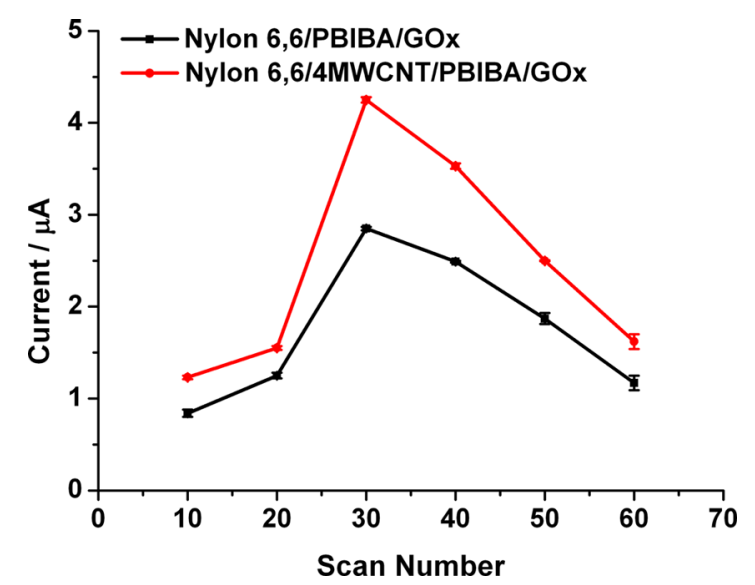

Figure 2. Effects of scan number on the biosensor response (in sodium acetate buffer, $50 \mathrm{mM}, \mathrm{pH} 5.5,25^{\circ} \mathrm{C},-0.7 \mathrm{~V}$, [Glucose: 0.4 $\mathrm{mM}]$ ). Error bars show standard deviation of three measurements.

An increase in the polymer thickness on the surface may cause a longer diffusion distance between the biomolecule and the transducer. Thus, the electrons resulting from the biocatalytic reactions cannot be efficiently transferred through the electrode, and the current responses for glucose decrease. However, for a low thickness of polymer, the functional groups on the surface may not be sufficient to attach the biomolecule, and enzyme may leach from the surface, resulting in low responses. Furthermore, a huge recognition element cannot be stabilized on the polymer layer. According to amperometric results, 30 scans revealed the best result, and so that was chosen as the optimum scan number in electropolymerization.

During optimization studies, the different amount of GOx (varied from 25 to $120 \mathrm{U}$ in $50 \mathrm{mM}$ sodium phosphate buffer, $\mathrm{pH}$ 7.5) was immobilized on modified polymer surfaces having optimum thickness with the help of GA. The highest signals were recorded for $50 \mathrm{U}$ GOx for each biosensor (Figure 3). The high amount of enzyme may not be stabilized on the

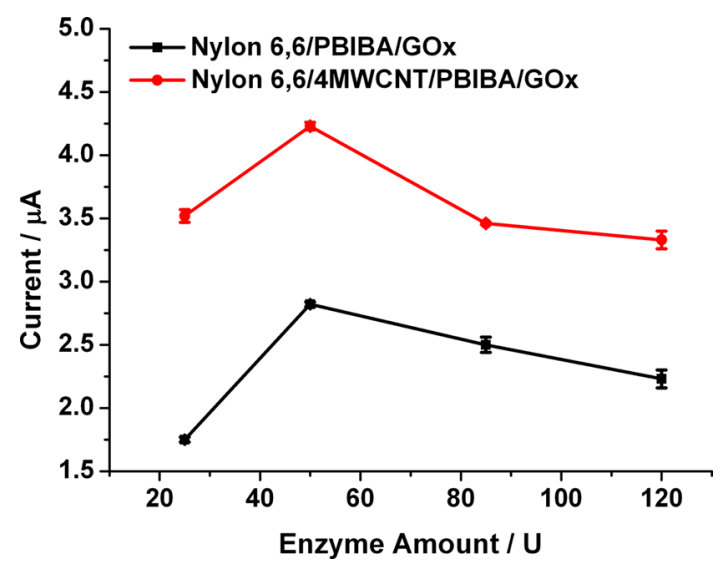

Figure 3. Effects of enzyme amount on the biosensor response (in sodium acetate buffer, $50 \mathrm{mM}, \mathrm{pH} 5.5,25^{\circ} \mathrm{C},-0.7 \mathrm{~V}$, [Glucose: 0.4 $\mathrm{mM}]$ ). Error bars show standard deviation of three measurements.

surface due to a lack of enough functional groups of polymer for a covalent bond. Therefore, the optimum enzyme amount was used for further experiments.

A bifunctional GA molecule was generally preferred to stabilize enzyme molecules on the polymer matrix via crosslinking technique. However, a high concentration of GA may cause intercrosslinking of enzyme molecules. Thus, the active sides of protein are eliminated, and the amperometric response to substrate decreases due to reduction of bioactive reactions. To determine the effect of GA amount on biosensing performance, the optimized biosensors including different GA amounts $(0.05 \%, 0.10 \%, 0.50 \%, 1.00 \%)$ were fabricated and tested for $0.4 \mathrm{mM}$ glucose. The optimum amount of GA was identified as $0.10 \%$.

Since enzyme molecules may be denatured under extreme $\mathrm{pH}$ values, the optimum microenvironment conditions should be assured to enhance the biosensor performance. Exploring the effect of $\mathrm{pH}$ on biosensing, an optimum biosensor was prepared for all nanofibrous composite modified surfaces. Optimization studies were achieved in different buffer medium with various $\mathrm{pH}$ values varying between 4.5 and $6.5(50 \mathrm{mM}$ sodium acetate buffer at $4.5,5.0$, and 5.5 and $50 \mathrm{mM}$ phosphate buffer at 6.0 and $6.5 ; 25{ }^{\circ} \mathrm{C}$ ). Considering the amperometric current results, $\mathrm{pH} 5.5$ was determined as the optimum value (Supporting information Figure S1).

The effect of MWCNT amount on biosensing performance was investigated by changing the $\mathrm{CNT}$ ratio in the mixture solutions for electrospinning. Throughout the preparation of nylon 6,6/MWCNT solutions, purified MWCNTs were added to nylon 6,6 solutions in proportion to $1 \%, 2 \%$, and $4 \%(\mathrm{w} / \mathrm{w})$, respectively, and desired electrospun nanofibers were collected on graphite electrodes. Afterwards, three glucose biosensors were constructed for the optimum conditions and tested for different substrate concentrations. The amperometric results were indicated in Figure 4.

An increase in CNT ratio in nanocomposite film provides the high electron transfer ability; hence, amperometric response rises due to the high amount of CNTs. Moreover, the morphology of the surface changes in the presence of CNTs. Since the electroactive species and porosity on the surface layer increase, a large amount of CP (PBIBA) was coated on the nanofibers. This situation allows a high amount of GOx to be covalently loaded in the polymer matrix. In this research, the optimum MWCNT ratio was determined as $4.0 \%$ addition to 


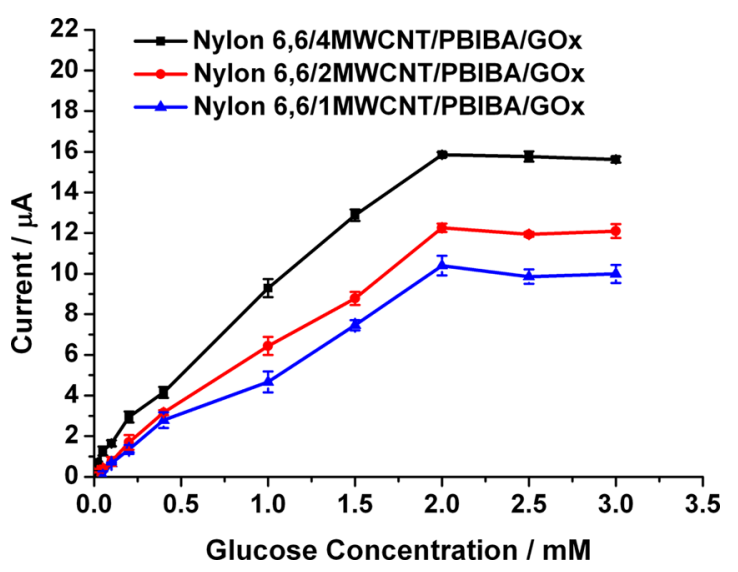

Figure 4. Effect of MWCNT amount on the biosensor response (in 50 $\mathrm{mM}$ sodium acetate buffer, $\left.\mathrm{pH} 7.0,25{ }^{\circ} \mathrm{C},-0.7 \mathrm{~V}\right)$. Error bars show the standard deviation of three measurements.

nylon 6,6 solution. The effect of the MWCNT is also consistent with $\mathrm{CV}$ results which prove the increase in electroactive species on the electrode surface with the addition of CNTs.

3.3. Surface Characterization. It was already reported in our previous work that $8 \%(\mathrm{w} / \mathrm{v})$ nylon 6,6 was an optimum concentration to obtain uniform and bead-free nylon 6,6 nanofibers for formic acid as a solvent system. ${ }^{47}$ The average fiber diameter (AFD) of the nylon 6,6 nanofibers was determined as $70 \pm 20 \mathrm{~nm}$ for the nylon 6,6/formic acid system (Figure 5a). Nylon 6,6/1MWCNT, nylon 6,6/
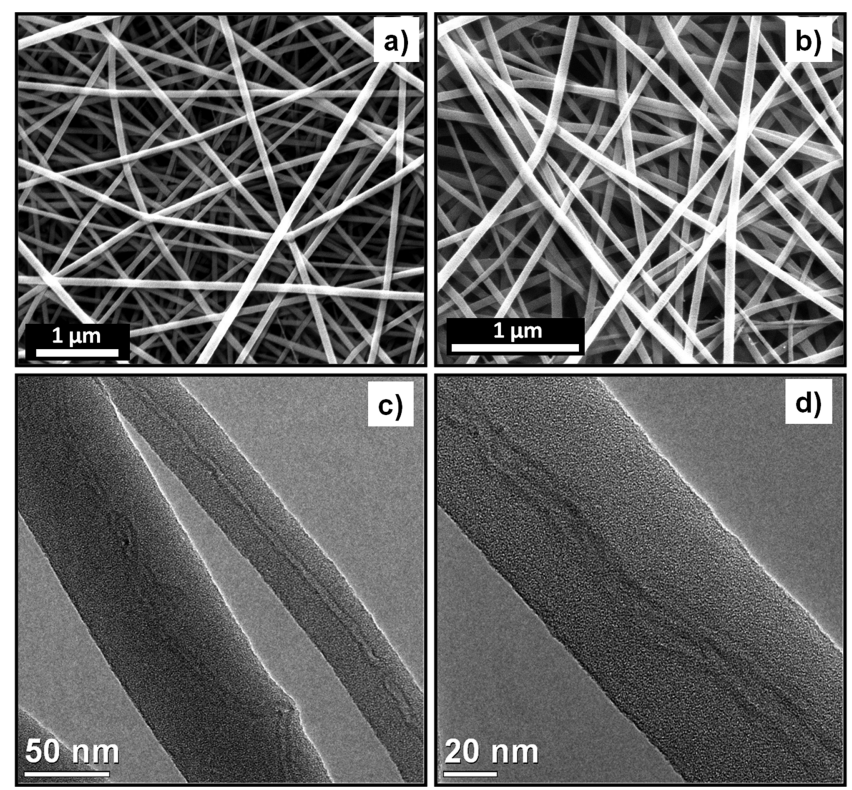

Figure 5. (a) Representative SEM image of nylon 6,6, (b) SEM image of nylon 6,6/4MWCNT, and (c) and (d) TEM images of nylon 6,6/ 4MWCNT nanofibers under optimized conditions.

2MWCNT, and nylon 6,6/4MWCNT nanofibers were also bead-free. The scanning electron microscope (SEM) image of nylon 6,6/4MWCNT is indicated in Figure $5 \mathrm{~b}$ as a representative. Bead formation is the common defect for electrospun nanofibers. Smooth nanofibers without beads are required to decrease the variability of the morphology and thus supply reproducibility. ${ }^{48-50}$ Moreover, the bead formation may lead to aggregation of colloids in the case of electrospinning of suspensions. ${ }^{48}$ Here, bead-free nanofibers were obtained to provide homogenous dispersion of MWCNTs in the composite electrospun nanofibers. The nylon 6,6 solution containing 5\% (w/w) MWCNT could not be electrospun since 5\% (w/w) MWCNT agglomerates in the solution without proper dispersion are possible because of strong van der Waals interactions between MWCNTs. ${ }^{51-53}$

The decrease in AFD with an increase of CNT concentration generating higher charge density in the solution is generally reported in the literature. ${ }^{52,54,55}$ When the AFD of the nylon 6,6/4MWCNT was compared with pristine nylon 6,6 nanofibers, no obvious change was observed in AFD with low CNT concentrations $(1-2 \%(\mathrm{w} / \mathrm{w}))$ that were probably not enough to increase the solution conductivity. The trivial AFD decreasing effect could only be observed in the nylon 6,6/ $4 \mathrm{MWCNT}$ system $(60 \pm 10 \mathrm{~nm})$ possibly due to an increase in the solution conductivity. To clarify this, the conductivity of the corresponding solutions was measured, and it was recorded as $3.34 \mu \mathrm{S} / \mathrm{cm}$ for pristine nylon 6,6 and $5.06 \mu \mathrm{S} / \mathrm{cm}$ for nylon $6,6 / 4 \mathrm{MWCNT}$ solutions. The nanofiber diameter decreases with the increase in conductivity of the solution resulting in higher stretching of polymer solution under the high electrical field. $^{56}$ The morphologies of the nylon 6,6/4MWCNT nanofibers were further investigated by high-resolution transmission electron microscope (HRTEM). The representative HRTEM images of nylon 6,6/4MWCNT nanofibers are given in Figure 5c,d. It is clearly shown that MWCNTs having tubular structure $(7-15 \mathrm{~nm}$ in diameter) aligned parallel to the fiber axis are possibly due to sink flow (Hamel flow) and high extension forces of the electrospun jet. ${ }^{52,57}$ This observation suggests that MWCNTs are well dispersed in the solution. ${ }^{52,53}$

The morphology of layer-by-layer modified electrode surfaces was characterized via SEM. Figure 6a,b represents the SEM images of conductive polymer (PBIBA) coated nylon 6,6 and nylon 6,6/4MWCNT surfaces, respectively. It is clearly seen that the CP uniformly wrapped around the nanofibers. Therefore, these images obviously proved that the unique structures of nanofibers were protected during the electro-

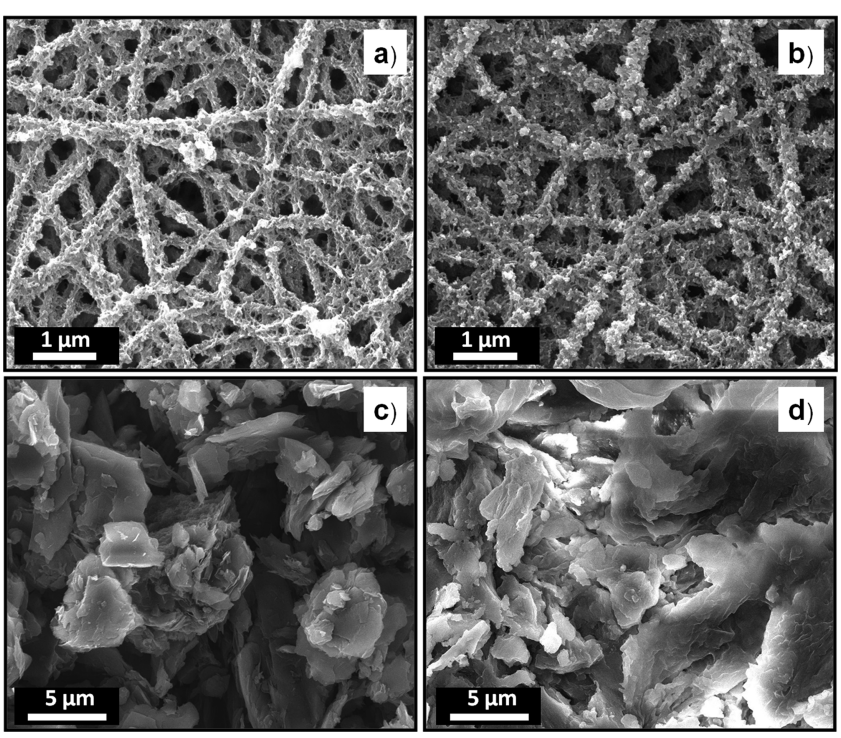

Figure 6. Representative SEM images of (a) nylon 6,6/PBIBA and (b) nylon 6,6/4MWCNT/PBIBA surfaces before GOx immobilization and (c) nylon 6,6/PBIBA and (d) nylon 6,6/4MWCNT/PBIBA surfaces after GOx immobilization under optimized conditions. 
polymerization process. The porous morphology of the nanofibers allowed the homogeneous electropolymerization of the monomer through all the fiber surfaces. Such a surface design leads to a drastic increase in the surface area of the coated CP. Due to the rough structure of surfaces, enzyme molecules can penetrate into the polymeric layer. Moreover, an increase in the aldehyde group of the PBIBA polymer on an electrode provides robust covalent interaction of GOx. Owing to the high surface area, the protein molecules are well adhered onto this nanofibrous composite surface. After immobilization of enzyme, surface morphology was drastically changed. The images in Figure 6c,d illustrate the enzyme immobilized surfaces and prove that the well-organized GOx completely have covered electrode surfaces.

The surfaces before and after GOx immobilization were also characterized via XPS technique, and the corresponding peaks were resolved in a fitting program. For the nylon 6,6/ 4MWCNT/PBIBA/GOx biosensor having the best results, C 1s peaks of the layers were depicted in the Supporting Information. Due to the excellent coverage of the PBIBA polymer around the electrospun nanofibers, PBIBA polymer properties dominate the nylon 6,6/4MWCNT nanofiber surface characteristics. According to these results, the absence of the peak belongs to the $\mathrm{C}$ atom of the $\mathrm{C}=\mathrm{O}$ group, and the increase in $\mathrm{C}$ atom intensity of $\mathrm{C}=\mathrm{N}$ prove the presence of imine bond formation between the PBIBA polymer and enzyme molecules (Supporting Information, Figure S3). As another surface characterization technique, contact angle determination was used for identifying the hydrophilic or hydrophobic properties of corresponding surfaces. On the basis of the measurements the surface characteristics of each layer were determined using distilled water for each coating. According to the experimental results, the contact angles were determined as $66.65 \pm 0.76^{\circ}$ for nylon $6,6 /$ PBIBA and $67.81 \pm 2.57^{\circ}$ for nylon 6,6/4MWCNT/PBIBA surfaces, respectively. The contact angle of the commercial nylon 6,6 surface was reported as $75.9^{\circ} \pm 2.2^{\circ}$ in the literature. ${ }^{58}$ After GOx immobilization, contact angle values of surfaces were drastically changed and measured as $35.21 \pm 2.06^{\circ}$ for nylon 6,6/PBIBA/GOx and $24.29 \pm 2.91^{\circ}$ for nylon 6,6/4MWCNT/ PBIBA/GOx surfaces. After attachment of GOx to the surfaces, hydrophilic character was observed due to carboxylic acid groups. Whereas polymers are generally known as hydrophobic materials, carboxylic acid containing surfaces show hydrophilic character. ${ }^{59}$

3.4. Analytical Characterization. The electroanalytic characterization of biosensors was performed using the amperometric detection technique. The molecular oxygen is reduced to hydrogen peroxide in the presence of glucose with the applied potential of $-0.7 \mathrm{~V}$ to the cathode. During the enzymatic redox reactions, the oxidation of the glucose to glucono- $\delta$-lactone (and further hydrolysis to gluconic acid) is provided by the reduction of flavin adenine dinucleotide (FAD) to $\mathrm{FADH}_{2}$, the redox couple of GOx. The diffusion rate of the oxygen from the bulk is proportional to the glucose concentration. $^{60,61}$ Thus, the consumption of the oxygen can be easily monitored via the current change during the catalytic reactions. ${ }^{62}$ In such electronic systems, CPs can be utilized to shuttle the electrons between a redox center of GOx and a transducer. ${ }^{63-65}$ For the corresponding biosensor constructions in this study, nylon 6,6 and nylon 6,6/4MWCNT nanofibers were coated with PBIBA as a CP. Thus, nylon 6,6 nanofibers do not play an active role during the electron transfer. The electron mobility succeeds by the hopping process between redox centers of a covalently bound biomolecule and the CP backbone. Since oxygen consumption during the enzymatic redox reaction was achieved at $-0.7 \mathrm{~V}$ constant potential, current responses versus time values were recorded at this potential. The calibration curves including varying glucose concentration versus current were established for optimum electrodes (Figure 7). The linear ranges were observed as

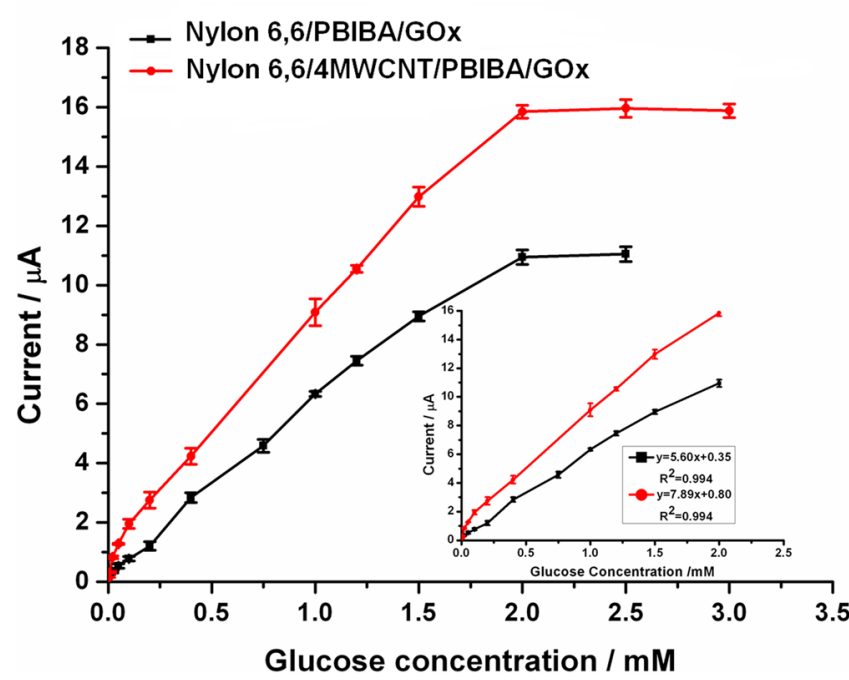

Figure 7. Calibration curves for glucose and linear ranges (in sodium acetate buffer, $50 \mathrm{mM}, \mathrm{pH} 5.5,25{ }^{\circ} \mathrm{C},-0.7 \mathrm{~V}$ ). Error bars show standard deviation of three measurements.

0.02-2.0 $\mathrm{mM}$ and $0.01-2.0 \mathrm{mM}$ for nylon 6,6/PBIBA/GOx and nylon 6,6/4MWCNT/PBIBA/GOx biosensors. Kinetic parameters were calculated from the Lineweaver-Burk plot at constant temperature and $\mathrm{pH}$ 5.5. $\mathrm{K}_{\mathrm{m}}{ }^{\text {app }}$ values were calculated for nylon 6,6/PBIBA/GOx and nylon 6,6/4MWCNT/PBIBA/ GOx biosensors as 1.01 and $1.86 \mathrm{mM}$, respectively. Since the electrode surfaces were modified with various materials, the morphology of these immobilization platforms showed different characteristics after CP coating. Thus, different amounts of enzyme can be efficiently attached on these electroactive matrices. This robust binding allows the easy accessibility of substrate from the bulk to the enzyme. This situation leads to a decrease in $K_{\mathrm{m}}{ }^{\text {app }}$ values. Hence, nylon 6,6/PBIBA/GOx has a higher affinity for the substrate than nylon 6,6/4MWCNT/ PBIBA/GOx. $I_{\max }$ values representing the maximum current measured at substrate saturation were determined as 10.03 and 16.67 $\mu \mathrm{A}$ for nylon 6,6/PBIBA/GOx and nylon 6,6/ 4MWCNT/PBIBA/GOx biosensors. In addition, limit of detection (LOD) values were calculated considering the following equation: $\mathrm{LOD}=3 \sigma / \mathrm{S}$. In this equation 3 represents the signal to noise ratio, $\sigma$ the standard deviation of three measurements of blank solution, and $S$ the slope of the linear regression equation of the lowest concentration value. According to these calculations, the LOD values of corresponding biosensors were determined as 18 and $9.0 \mu \mathrm{M}$ for the corresponding nylon 6,6 and nylon 6,6/4MWCNT modified biosensors, respectively (Table 1). Additionally, operational and storage stabilities of each biosensor were measured. Due to the operational stability measurement results, there exists no decrease subsequent for 64 measurements for nylon 6,6/PBIBA/GOx and 78 measurements for nylon 6,6/ 
Table 1. Comparison of Glucose Biosensors in the Literature ${ }^{a}$

\begin{tabular}{lccll}
\multicolumn{1}{c}{ immobilization matrix } & limit of detection $(\mu \mathrm{M})$ & $K_{\mathrm{m}}^{\text {app }}(\mathrm{mM})$ & \multicolumn{1}{c}{ linear range } & \multicolumn{1}{c}{ reference } \\
carbon nanofibers (CNF) & 2.50 & $\mathrm{NR}$ & $2.0 \mu \mathrm{M}-2.5 \mathrm{mM}$ & 65 \\
Ni NP loaded CNFs & 1.00 & $\mathrm{NR}$ & $2.0 \mu \mathrm{M}-2.5 \mathrm{mM}$ & 66 \\
Au/poly(o-aminophenol/carbon nanotubes) & 10.00 & 22.80 & $\mathrm{NR}$ & 8 \\
PVS/PAMAM-Au NPs@CoHCF & 17.00 & 2.03 & up to $1.5 \mathrm{mM}$ & 67 \\
dithiol/Au NPs/cysteamine & 8.20 & 4.30 & $0.2 \mu \mathrm{M}-5.70 \mathrm{mM}$ & 68 \\
PBIBA & 2.29 & 0.94 & $0.02-1.2 \mathrm{mM}$ & 43 \\
nylon 6,6/PBIBA & 18.00 & 1.01 & $0.02-2.0 \mathrm{mM}$ & this work \\
nylon 6,6/4MWCNT/PBIBA & 9.00 & 1.86 & $0.01-2.0 \mathrm{mM}$ & this work \\
a (NR: not reported). & & & &
\end{tabular}

4MWCNT/PBIBA/GOx biosensors. The shelf life of the modified electrodes was determined for the same glucose concentration $(40 \mathrm{mM})$. The amperometric measurements were achieved during 32 days for nylon 6,6/PBIBA/GOx and 44 days for nylon 6,6/4MWCNT/PBIBA/GOx biosensors. There is no decrease in the current responses of the same glucose concentration during these times.

Although the glucose biosensors have been investigated over five decades, up to date electrospun nanofiber modified ones were rarely studied to the best of our knowledge. In 2007, Wu et al. reported a glucose biosensor with carbon nanofibers (CNFs). ${ }^{65}$ This biosensor showed good linearity $(2 \mu \mathrm{M}-2.5$ $\mathrm{mM})$ with low LOD value $(2.50 \mu \mathrm{M})$. A nonenzymatic glucose biosensor was constructed using gold-modified CNFs by Liu et al. where a very low detection limit of $1.0 \mu \mathrm{M}$ was reported. ${ }^{66}$ Other selected examples were summarized with their linear range, LOD, and $K_{\mathrm{m}}{ }^{\text {app }}$ values in Table 1 . In our previous work, a novel CP (PBIBA) based glucose biosensor was reported with low LOD and excellent substrate affinity. ${ }^{38}$ In our further investigations, nylon 6,6/PBIBA and nylon 6,6/4MWCNT/ PBIBA modified biosensors showed better linearity and operational stability. Moreover, the nylon 6,6/4MWCNT/ PBIBA/GOx biosensor has the highest $I_{\max }$ value among the selected examples from the literature. Since the electron transfer ability of this biosensor was upgraded, the amperometric current responses increased for the same amount of substrate.

In addition, the effect of possible interferent materials such as ascorbic acid, urea, and oxalic acid was investigated for generated biosensors to obtain high accuracy in real sample applications. During these studies, the proposed materials were added into the buffer solution ( $50 \mathrm{mM}$ sodium acetate, $\mathrm{pH} 5.5$ ) instead of glucose substrate, and amperometric measurements were carried out at $-0.7 \mathrm{~V}$. For different concentrations of these materials $(0.1$ and $0.01 \mathrm{M})$, a negligible interference effect was observed in giving conditions (Supporting Information, Figure S2).

3.5. Sample Application. To investigate the reliability and performance of the nylon 6,6/PBIBA/GOx and nylon 6,6/ 4MWCNT/PBIBA/GOx biosensors, the glucose levels in several beverages were determined for the optimum conditions. In these applications, preferred beverage solutions were added into the buffer ( $50 \mathrm{mM}$ sodium acetate, $\mathrm{pH} 5.5$ ) without any dilution. Then, corresponding results were compared to the results obtained with spectrophotometric techniques in Table 2. Results prove that there is no significant difference between two techniques showing the reliability and accuracy of two novel biosensors. Even though the corresponding biosensor results seem to be similar for the chosen real samples, the nylon 6,6/4MWCNT/PBIBA/GOx biosensor had the lowest LOD
Table 2. Glucose Analysis with Various Beverages

\begin{tabular}{lccc}
\multicolumn{1}{c}{ samples } & $\begin{array}{c}\text { spectroscopic } \\
(\mathrm{mol} / \mathrm{L})\end{array}$ & $\begin{array}{c}\text { nylon 6,6/PBIBA } \\
\text { modified } \\
(\mathrm{mol} / \mathrm{L})\end{array}$ & $\begin{array}{c}\text { nylon 6,6/PBIBA/ } \\
\text { 4MWCNT modified } \\
(\mathrm{mol} / \mathrm{L})\end{array}$ \\
$\begin{array}{c}\text { U brand } \\
\text { lemonade }\end{array}$ & 0.035 & 0.028 & 0.038 \\
$\begin{array}{c}\mathrm{L} \text { brand ice tea } \\
\text { F brand peach } \\
\text { tea }\end{array}$ & 0.023 & 0.029 & 0.027 \\
$\begin{array}{c}\mathrm{C} \text { brand orange } \\
\text { juice }\end{array}$ & 0.048 & 0.021 & 0.025 \\
$\begin{array}{c}\mathrm{C} \text { brand lemon } \\
\text { juice }\end{array}$ & 0.022 & 0.050 & 0.047 \\
$\begin{array}{c}\text { L brand } \\
\text { pomegranate } \\
\text { juice }\end{array}$ & 0.030 & 0.020 & 0.021 \\
\hline
\end{tabular}

value and showed the highest operational stability and longest shelf life. Biosensor performance results show that the nylon 6,6/4MWCNT/PBIBA/GOx biosensor is more preferable in long-term studies for lower concentrations.

\section{CONCLUSIONS}

In this study, novel immobilization matrices were generated using nylon 6,6 and nylon 6,6/4MWCNT electrospun nanofibers. The modified electrodes were coated with recently synthesized CP PBIBA, and glucose biosensors of these nanofibrous composite surfaces were prepared to investigate their immobilization matrix properties. These fabricated biosensors exhibited high $I_{\max }$ with low LOD values and high affinity to substrates. The combination of the PBIBA and nanofibers served as excellent immobilization matrix properties for a long period stability by means of robust covalent bonds between GOx and nanofibrous composite coated surfaces. Moreover, the biosensors were successfully tested for glucosecontaining beverages with satisfactory results. According to the experimental results, MWCNT incorporation to nylon 6,6 nanofibers provided the good stability, prolonged shelf life, and high electron transfer ability for the proposed biosensor. These electrospun surface-modified biosensors have promising potentials for development of various electrochemical biosensors including detection of many analytes such as protein, DNA/RNA, alcohol, cholesterol etc. due to their high surface area and design flexibility.

\section{ASSOCIATED CONTENT}

\section{Supporting Information}

Materials, apparatus, and polymer synthesis. This material is available free of charge via the Internet at http://pubs.acs.org. 


\section{AUTHOR INFORMATION}

\section{Corresponding Authors}

*E-mail: tamer@unam.bilkent.edu.tr. Tel.: +90 3122903571.

Fax: +90 3122664365 (T.U.).

*E-mail: toppare@metu.edu.tr (L.V.).

\section{Author Contributions}

The manuscript was written through contributions of all authors. All authors have given approval to the final version of the manuscript. All authors contributed equally.

Notes

The authors declare no competing financial interest.

\section{ACKNOWLEDGMENTS}

Dr. T. Uyar acknowledges EU FP7-PEOPLE-2009-RG Marie Curie-IRG (NANOWEB, PIRG06-GA-2009-256428) and The Turkish Academy of Sciences - Outstanding Young Scientists Award Program (TUBA-GEBIP) for partial funding of the research. F. Kayaci acknowledges TUBITAK-BIDEB for National PhD Scholarship.

\section{ABBREVIATIONS}

MWCNT, multiwalled carbon nanotube; PBIBA, poly-4-(4,7di(thiophen-2-yl)-1H-benzo[d]imidazol-2-yl)benzaldehyde; HR-TEM, high-resolution transmission electron microscopy; SEM, scanning electron microscope; $\mathrm{CP}$, conducting polymer; CNT, carbon nanotubes; SWCNT, single-walled carbon nanotube; DWCNT, double-walled carbon nanotube; GOx, glucose oxidase; CV, cyclic voltammogram; GA, glutaraldehyde; AFD, average fiber diameter; LOD, limit of detection

\section{REFERENCES}

(1) Ak, M.; Ak, M. S.; Kurtay, G.; Güllü, M.; Toppare, L. Synthesis and Electropolymerization of 1,2-bis(thiophen-3-ylmethoxy)benzene and Its Electrochromic Properties and Electrochromic Device Application. Solid State Sci. 2010, 1199-1204.

(2) Zhang, L. L.; Zhao, S.; Tian, X. N.; Zhao, X. S. Layered Graphene Oxide Nanostructures with Sandwiched Conducting Polymers as Supercapacitor Electrodes. Langmuir 2010, 17624-17628.

(3) Guo, B.; Glavas, L.; Albertsson, A.-C. Biodegradable and Electrically Conducting Polymers for Biomedical Applications. Prog. Polym. Sci. 2013, 1263-1286.

(4) Gupta, N.; Sharma, S.; Mir, I. A.; Kumar, D. Advances in Sensors Based on Conducting Polymers. J. Sci. Ind. Res. 2006, 549-557.

(5) Soylemez, S.; Kanik, F. E.; Uzun, S. D.; Hacioglu, S. O. Development of an Efficient Immobilization Matrix Based on a Conducting Polymer and Functionalized Multiwall Carbon Nanotubes: Synthesis and Its Application to Ethanol Biosensors. J. Mater. Chem. B 2014, 511-521.

(6) Kesik, M.; Kanik, F. E.; Hızalan, G.; Kozanoglu, D.; Esentürk, E. N.; Timur, S.; Toppare, L. A Functional Immobilization Matrix Based on a Conducting Polymer and Functionalized Gold Nanoparticles: Synthesis and Its Application as an Amperometric Glucose Biosensor. Polymer 2013, 4463-4471.

(7) Kumar, A.; Jung, S.; Ji, T. Protein Biosensors Based on Polymer Nanowires, Carbon Nanotubes and Zinc Oxide Nanorods. Sensors 2011, 5087-5111.

(8) Pan, D.; Chen, J.; Yao, S.; Tao, W.; Nie, L. An Amperometric Glucose Biosensor Based on Glucose Oxidase Immobilized in Electropolymerized Poly(o-aminophenol) and Carbon Nanotubes Composite Film on a Gold Electrode. Anal. Sci. 2005, 367-374.

(9) Singh, S.; Solanki, P. R.; Pandey, M. K.; Malhotra, B. D. Cholesterol biosensor based on cholesterol esterase, cholesterol oxidase and peroxidase immobilized onto conducting polyaniline films. Sens. Actuators, B 2006, 534-541.
(10) Curulli, A.; Valentini, F.; Orlanducci, S.; Terranova, M. L.; Palleschi, G. Pt based enzyme electrode probes assembled with Prussian Blue and conducting polymer nanostructures. Biosens. Bioelectron. 2004, 1223-1232.

(11) Habermüller, K.; Mosbach, M.; Schuhmann, W. ElectronTransfer Mechanisms in Amperometric Biosensors. Fresenius J. Anal. Chem. 2000, 560-568.

(12) Cosnier, S. Biomolecule Immobilization on Electrode Surfaces by Entrapment or Attachment to Electrochemically Polymerized films: A review. Biosens. Bioelectron. 1999, 443-456.

(13) Demirci, S.; Emre, F. B.; Ekiz, F.; Oğuzkaya, F.; Timur, S.; Tanyeli, C.; Toppare, L. Functionalization of poly-SNS-anchored Carboxylic Acid with Lys and PAMAM: Surface Modifications for Biomolecule Immobilization/Stabilization and Bio-sensing Applications. Analyst 2012, 4254-4261.

(14) Iijima, S. Helical Microtubules of Graphitic Carbon. Nature 1991, 56-58.

(15) Bachtold, A.; Hadley, P.; Nakanishi, T.; Dekker, C. Logic Circuits with Carbon Nanotube Transistors. Science 2001, 1317-1320.

(16) Wang, Y.; Zhitomirsky, I. Nanotube Composites for Electrochemical Supercapacitors. Langmuir 2009, 9684-9689.

(17) Kasumov, A. Y.; Deblock, R.; Kociak, M.; Reulet, B.; Bouchiat, H.; Khodos, I. Supercurrents Through Single-Walled Carbon Nanotubes. Science 1999, 1508-1511.

(18) Wang, P.; Ma, J.; Wang, Z.; Shi, F.; Liu, Q. Enhanced Separation Performance of PVDF/PVP-g-MMT Nanocomposite Ultrafiltration Membrane Based on the NVP-Grafted Polymerization Modification of montmorillonite (MMT). Langmuir 2012, 4776-4786.

(19) Vashist, S. K.; Zheng, D.; Rubeaan, K. A.; Luong, J. H. T.; Sheu, F. S. Advances in Carbon Nanotube Based Electrochemical Sensors for Bioanalytical Applications. Biotechnol. Adv. 2011, 169-188.

(20) Liu, Y.; Lu, N.; Poyraz, S.; Wang, X.; Yu, Y.; Scott, J.; Smith, J.; Kim, M. J.; Zhang, X. One-pot Formation of Multifunctional PtConducting Polymer Intercalated Nanostructures. Nanoscale 2013, 3872-3879.

(21) Lebedev, N.; Trammell, S. A.; Tsoi, S.; Spano, A.; Kim, J. H.; $\mathrm{Xu}$, J.; Twigg, M. E.; Schnur, J. M. Increasing Efficiency of Photoelectronic Conversion by Encapsulation of Photosynthetic Reaction Center Proteins in Arrayed Carbon Nanotube Electrode. Langmuir 2008, 8871-8876.

(22) Gooding, J. J.; Wibowo, R.; Liu, J.; Yang, W.; Losic, D.; Orbons, S.; Mearns, F. J.; Shapter, J. G.; Hibbert, D. B. Protein Electrochemistry Using Aligned Carbon Nanotube Arrays. J. Am. Chem. Soc. 2003, 9006-9007.

(23) Cao, Y. W.; Jin, R; Mirkin, C. A. DNA-Modified Core-Shell Ag/ $\mathrm{Au}$ Nanoparticles. J. Am. Chem. Soc. 2001, 7961-7962.

(24) Jiang, S. H.; Hou, H. Q.; Greiner, A.; Agarwal, S. Tough and Transparent nylon-6 Electrospun Nanofiber Reinforced MelamineFormaldehyde Composites. ACS Appl. Mater. Interfaces 2012, $2597-$ 2603.

(25) Huang, S.; Ding, Y.; Liu, Y. X.; Su, L.; Filosa, R., Jr.; Lei, Y. Glucose Biosensor Using Glucose Oxidase and Electrospun $\mathrm{Mn}_{2} \mathrm{O}_{3}-\mathrm{Ag}$ Nanofibers. Electroanalysis 2011, 1912-1920.

(26) Kayaci, F.; Umu, O. C. O.; Tekinay, T.; Uyar, T. Antibacterial Electrospun Polylactic Acid (PLA) Nanofibrous Webs Incorporating Triclosan/Cyclodextrin Inclusion Complexes. J. Agric. Food Chem. 2013, 3901-3908.

(27) Maas, M.; Guo, P.; Keeney, M.; Yang, F.; Hsu, T. M.; Fuller, G. G.; Martin, C. R.; Zare, R. N. Preparation of Mineralized Nanofibers: Collagen Fibrils Containing Calcium Phosphate. Nano Lett. 2011, $1383-1388$

(28) Canbolat, M. F.; Celebioglu, A.; Uyar, T. Drug Delivery System Based on Cyclodextrin-Naproxen Inclusion Complex Incorporated in Electrospun Polycaprolactone Nanofibers. Colloids Surf. B 2014, 1521.

(29) Marx, S.; Jose, M. V.; Andersen, J. D.; Russell, A. J. Electrospun Gold Nanofiber Electrodes for Biosensors. Biosens. Bioelectron. 2011, 2981-2986. 
(30) Scampicchio, M.; Arecchi, A.; Bianco, A.; Bulbarello, A.; Bertarelli, C.; Mannino, S. Nylon nanofibrous biosensors for glucose determination. Electroanalysis 2010, 1056-1060.

(31) Arecchi, A.; Scampicchio, M.; Brenna, O. V.; Mannino, S. Biocatalytic nylon nanofibrous membranes. Anal. Bioanal. Chem. 2010, 3097-3103.

(32) Jeong, J.; Jeon, S.; Lee, T.; Park, J.; Shin, J.; Alegaonkar, P.; Berdinsky, A.; Yoo, J. Fabrication of MWNTs/nylon Conductive Composite Nanofibers by Electrospinning. Diamond Relat. Mater. 2006, 1839-1843.

(33) Scampicchio, M.; Arecchi, A.; Lawrence, N. S.; Mannino, S. Nylon Nanofibrous Membrane for Mediated Glucose Biosensing. Sens. Actuators, B 2010, 394-397.

(34) Arecchi, A.; Scampicchio, M.; Drusch, S.; Mannino, S. Nanofibrous Membrane Based Tyrosinase-Biosensor for the Detection of Phenolic Compounds. Anal. Chim. Acta 2010, 133-136.

(35) Lala, N. L.; Thavasi, V.; Ramakrishna, S. Preparation of Surface Adsorbed and Impregnated Multi-walled Carbon Nanotube/nylon-6 nanofiber Composites and Investigation of Their Gas Sensing Ability. Sensors 2009, 86-101.

(36) Zhang, W. D.; Shen, L.; Phang, I. Y.; Liu, T. Carbon Nanotubes Reinforced Nylon-6 Composite Prepared by Simple Melt-Compounding. Macromolecules 2004, 256-259.

(37) Naebe, M.; Lin, T.; Wang, X. Carbon Nanotubes Reinforced Electrospun Polymer Nanofibers [online]. Nanofibers; Kumar, A., Ed.; 2010; Chapter 16, pp 309-328. DOI: 10.5772/8160. Available from: http://www.intechopen.com/books/nanofibers/carbon-nanotubesreinforcedelectrospun-polymer-nanofibres (accessed: February 1, 2010).

(38) Wang, X.; Wang, X.; Wang, X.; Chen, F.; Zhu, K.; Xu, Q.; Tang, M. Novel Electrochemical Biosensor Based on Functional Composite Nanofibers for Sensitive Detection of p53 Tumor Suppressor Gene. Anal. Chim. Acta 2013, 63-69.

(39) Choi, J.; Park, E. J.; Park, D. W.; Shim, S. E. MWCNT-OH Adsorbed Electrospun Nylon 6,6 Nanofibers Chemiresistor and Their Application in Low Molecular Weight Alcohol Vapours Sensing. Synth. Met. 2010, 2664-2669.

(40) Borges, A. L. S.; Souza, A. C.; Paes, T. J. A., Jr; Yoshida, T.; Buttino, M. C. Multiwalled Carbon Nanotube/Nylon-6 NanofiberReinforced Dental Composite. Dent. Mater. 2013, e34-e35.

(41) Endo, M.; Koyama, S.; Matsuda, Y.; Hayashi, T.; Kim, Y. A. Thrombogenicity and Blood Coagulation of a Microcatheter Prepared from Carbon Nanotube-Nylon-Based Composite. Nano Lett. 2005, 101-105.

(42) Leskovac, V.; Trivic, S.; Wohlfahrt, G.; Kandra, J.; Pericin, D. Glucose Oxidase from Aspergillus Niger: The Mechanism of Action with Molecular Oxygen, Quinones, and One-Electron Acceptors. Int. J. Biochem. Cell B 2005, 731-750.

(43) Uzun, S. D.; Unlu, N. A.; Kanik, F. E.; Sendur, M.; Kanik, F. E.; Timur, S.; Toppare, L. A Novel Promising Biomolecule Immobilization Matrix: Synthesis of Functional Benzimidazole Containing Conducting Polymer and Its Biosensor Applications. Colloids Surf. B 2013, 74-80.

(44) Edwards, E. R.; Antunes, E. F.; Botelho, E. C.; Baldan, M. R.; Corat, E. J. Evaluation of Residual Iron in Carbon Nanotubes Purified by Acid Treatments. Appl. Surf. Sci. 2011, 641-648.

(45) Ohta-Fukuyama, M.; Miyake, Y.; Emi, S.; Yamano, T. Identification and Properties of the Prosthetic Group of Choline Oxidase from Alcaligenes sp. J. Biochem. 1980, 197-203.

(46) Moore, K. E.; Flavel, B. S.; Yu, J.; Abell, A. D.; Shapper, J. G. Increased Redox-active Peptide Loading on Carbon Nanotube Electrodes. Electrochim. Acta 2013, 206-211.

(47) Kayaci, F.; Ozgit, C.; Donmez, I.; Biyikli, N.; Uyar, T. PolymerInorganic Core-Shell Nanofibers by Electrospinning and Atomic Layer Deposition: Flexible Nylon-ZnO Core-Shell Nanofiber Mats and Their Photocatalytic Activity. ACS Appl. Mater. Interfaces 2012, 61856194.

(48) Crespy, D.; Friedemann, K.; Popa, A. M. Colloid-Electrospinning: Fabrication of Multicompartment Nanofibers by the
Electrospinning of Organic or/and Inorganic Dispersions and Emulsions. Macromol. Rapid Commun. 2012, 1978-1995.

(49) Fong, H.; Chun, I.; Reneker, D. Beaded Nanofibers Formed During Electrospinning. Polymer 1999, 4585-4592.

(50) Liu, Y.; He, J. H.; Yu, J. y.; Zeng, H. M. Controlling Numbers and sizes of beads in electrospun nanofibers. Polym. Int.. 2008, 632636.

(51) Sahoo, N. G.; Rana, S.; Cho, J. W.; Li, L.; Chan, S. H. Polymer Nanocomposites Based on Functionalized Carbon Nanotubes. Prog. Polym. Sci. 2010, 837-867.

(52) Sarkar, S.; Zou, J.; Liu, J.; Xu, C.; An, L.; Zhai, L. PolymerDerived Ceramic Composite Fibers with Aligned Pristine Multiwalled Carbon Nanotubes. ACS Appl. Mater. Interfaces 2010, 1150-1156.

(53) Baji, A.; Mai, Y.-W.; Wong, S.-C.; Abtahi, M.; Du, X. Mechanical Behavior of Self-Assembled Carbon Nanotube Reinforced Nylon 6,6 Fibers. Compos. Sci. Technol. 2010, 1401-1409.

(54) Mazinani, S.; Ajii, A.; Dubois, C. Fundamental Study of Crystallization, Orientation, and Electrical Conductivity of Electrospun PET/Carbon Nanotube Nanofibers. J. Polym. Sci., Part B: Polym. Phys. 2010, 2052-2064.

(55) Wu, D.; Shi, T.; Yang, T.; Sun, Y.; Zhai, L.; Zhou, W.; Zhang, M.; Zhang, J. Electrospinning of Poly(trimethylene terephthalate)/ Carbon Nanotube Composites. Eur. Polym. J. 2011, 284-293.

(56) Uyar, T.; Besenbacher, F. Electrospinning of uniform polystyrene fibers: The effect of solvent conductivity. Polymer 2008, 5336-5343.

(57) Dror, Y.; Salalha, W.; Khalfin, R. L.; Cohen, Y.; Yarin, A. L.; Zussman, E. Carbon Nanotubes Embedded in Oriented Polymer Nanofibers by Electrospinning. Langmuir 2003, 7012-7020.

(58) Zhang, L.; Zhang, X.; Dai, Z.; Wu, J.; Zhao, N.; Zhu, J. MicroNano Hierarchically Structured Nylon 6,6 Surfaces with Unique Wettability. J. Colloids Interface Sci. 2010, 116-119.

(59) Gong, X.; Griesser, H. J. Excitation Frequency Dependence of the Surface Properties and Composition of Plasma Polymers from Aldehyde Monomers. Plasmas Polym. 1997, 261-276.

(60) Peteu, S. F.; Emerson, D. R.; Worden, M. A Clark-type Oxidase Enzyme-based Amperometric Microbiosensor for Sensing Glucose, Galactose, or Choline. Biosens. Bioelectron. 1996, 1059-1071.

(61) Rahman, Md. M. A.; Ahammad, J. S.; Jin, J.-H.; Ahn, S. J.; Lee, J.-J. A Comprehensive Review of Glucose Biosensors Based on Nanostructured Metal-Oxides. Sensors 2010, 4855-4886.

(62) Doretti, L.; Ferrara, D. Covalently Immobilized Enzymes on Biocompatible Polymers for Amperometric Sensor Applications. Biosens. Bioelectron. 1996, 365-373.

(63) Trojanowicz, M.; Krawczyk, T.K.V. Electrochemical Biosensors Based on Enzymes Immobilized in Electropolymerized Films. Microchim. Acta 1995, 167-181.

(64) Cracknell, J.A.; Vincent, K.A.; Armstrong, F.A. Enzymes as Working or Inspirational Electrocatalysts for Fuel Cells and Electrolysis. Chem. Rev. (Washington, DC, U. S.) 2008, 2439-2461.

(65) Wu, L.; Zhang, X.; Ju, H. Amperometric Glucose Sensor Based on Catalytic Reduction of Dissolved Oxygen at Soluble Carbon Nanofiber. Biosens. Bioelectron. 2007, 479-484.

(66) Liu, Y.; Teng, H.; Hou, H.; You, T. Nonenzymatic Glucose Sensor Based on Renewable Electrospun Ni Nanoparticle-loaded Carbon Nanofiber Paste Electrode. Biosens. Bioelectron. 2009, 33293334.

(67) Crespilho, F. N.; Ghica, M. E.; Florescu, M. F.; Nart, C.; Oliveir, O. N., Jr.; Brett, C. M. A. A Strategy for Enzyme Immobilization on Layer-by-Layer Dendrimer-Gold Nanoparticle Electrocatalytic Membrane Incorporating Redox Mediator. Electrochem Commun. 2006, $1665-1670$

(68) Zhang, S.; Wang, N.; Yu, H.; Niu, Y.; Sun, C. Covalent Attachment of Glucose Oxidase to an Au Electrode Modified with Gold Nanoparticles for Use as Glucose Biosensor. Bioelectrochemistry 2005, 15-22. 